\title{
НАСЕЛЕНИЕ ИРКУТСКОЙ ОБЛАСТИ: ОСОБЕННОСТИ СОЦИАЛЬНОГО ПОЛОЖЕНИЯ В ПЕРИОД МИРОВЫХ ВОЙН
}

\begin{abstract}
АНнотАЦия. В статье на основе историко-сравнительного метода осуществляется корреляция факторов, влияющих на социальное положение населения региона в годы мировых войн. $K$ таким факторам отнесены смена политической парадигмы в условиях войны, различные формы помощи со стороны населения фронту, в том числе укрепление финансовой мощи страны, а также помощь наименее защищенным группам населения. В качестве самостоятельного фактора, оказывающего влияние на распределение социальных ресурсов, рассматриваются помощь эвакуированному населению, организация эвакогоспиталей и лечение раненных, обустройство и содержание военнопленных и др. Констатируется, что социальное положение населения в условиях обеих войн определялось во многом совпадающими факторами, однако характер социальной политики в условиях Великой Отечественной войны имел гораздо больше принципиальных отличий от аналогичных усилий государства в период Первой мировой. Это стало одной из основных причин того, что Советский Союз не только устоял, несмотря на несопоставимо большие разрушения и социальные нагрузки на население, но и победил объединенную Европу, реализовал ракетно-ядерный проект и утвердился в статусе сверхдержавы.
\end{abstract}

кЛЮчЕВЫЕ сЛОВА. Война; население; социальное положение; условия жизни; социальная политика.

ИНФОРМАЦИЯ О СТАТЬЕ. Дата поступления 29 апреля 2016 г.; дата принятия к печати 18 мая 2016 г.; дата онлайн-размещения 29 июля 2016 г.

A. V. Shalak

Baikal State University, Irkutsk, Russian Federation

\section{POPULATION OF IRKUTSK OBLAST: FEATURES OF SOCIAL STANDING DURING THE PERIOD OF WORLD WARS}

\begin{abstract}
On the basis of historical and comparative method, the article makes correlation of the factors that impact the social standing of the region's population during the years of the world wars. Such factors involve change of the political paradigm in military environment, various forms of the population's assistance to the front, including strengthening financial power of the country, as well as assistance to the least protected groups of population. By way of an independent factor that have an impact on distributing social resources, it considers assistance to the evacuated population, cleaning hospital services and treatment of the wounded, providing management facilities for enemy prisoners of war, and others. It states that the social standing of the population in terms of the both wars was largely determined by concurring factors but the character of the social policy during the Great Patriotic War had a lot more principal differences from the analogue efforts of the state during the First World War. It became one of the main causes of the fact that the Soviet Union not only withstood in spite of the incomparably greater destructions and social pressure for the population but overcame the united Europe, implemented the nuclear project and established its status as a superpower.

KEYWORDS. War; population; social standing; conditions of life; social policy.

ARTICLE INFO. Received April 29, 2016; accepted May 18, 2016; available online July $29,2016$.
\end{abstract}

(C) А. В. Шалак, 2016

\section{Baikal Research Journal}


К столетию с начала Первой мировой войны и 70 -летию Победы пополнился пласт исторической литературы о событиях, имевших отношение к этим судьбоносным датам. Государственным архивом Иркутской области был издан сборник документов, в котором нашли отражение различные социальные процессы в губернии в годы Первой мировой войны, еще два сборника документов были посвящены истории Великой Отечественной войны.

Чем дальше отдаляются от нас эти события, тем больше оснований рассматривать период 1914-1945 гг. как нечто целое - 30-летняя война. В данном случае речь идет о совсем небольшом по историческим меркам периоде, по сути, он включает жизнь одного поколения. Однако поколение, которое мы имели на выходе, выросло в условиях иного политического режима. Это, с одной стороны. С другой стороны, власть, как фактор, влияющий на социальное положение население, также была иная. Как следствие, в стране была иная социальная политика и иные политические последствия выхода страны из этой мировой битвы. При этом анализ такой проблемы, как условия жизни населения на входе в этот период и на выходе, позволяет утверждать о наличии многих параллелей.

В данной статье на основе историко-сравнительного метода исследуется корреляция различных факторов, влияющих на социальное положение различных групп населения и определяющих содержание условий жизни.

К числу таких фундаментальных факторов можно отнести сам факт войны, как проведение политики «иными, а именно насильственными средствами». Смена политической парадигмы, вовлечение населения в различные мобилизационные мероприятия самым серьезным образом повлияло на положение различных социальных слоев.

Сравнивая степень влияния войн на повседневную жизнь населения региона, отметим, что масштабы непосредственного вовлечения жителей региона как в военные действия на фронтах, так и в различного рода мобилизационные мероприятия существенно отличаются.

Согласно данным статистического ежегодника России на 1 января 1914 г. в Иркутской губернии проживало 750,2 тыс. чел., из них 385,4 тыс. мужчин и 364,8 тыс. женщин ${ }^{1}$. В разнообразной справочной литературе указывается, что удельный вес призванных во время Первой мировой войны в Иркутской губернии составлял $11,5 \%$. Несложные расчеты показывают, что 11,5 \% призванных по отношению к мужской части населения - это, примерно, 44,5 тыс. чел., или 6,6 \% населения губернии.

Приведенные расчеты коррелируются с аналогичными данными периода Великой Отечественной войны следующим образом. Перед войной в Иркутской области проживало 1351,8 тыс. чел. [1, с. 52], из них на фронт ушли более 200 тыс. чел. $(14,8$ \% населения области, если за основу взять минимальную цифру в 200 тыс. чел.), т. е. масштабы и «плотность» мобилизации в регионе в 1941-1945 гг. более чем в два раза выше, чем в сравнении с периодом Первой мировой. С этой точки зрения влияние Великой Отечественной войны на социальное положение населения, несомненно, более масштабно и глубоко.

Война всегда приводит к жесткому цивилизационному контролю, поэтому в начальный период это затронуло прежде всего интересы тех граждан, которые с началом боевых действий воспринимались как представители враждебной цивилизации. В 1914-1915 гг. имело место открытая зачистка германских и австрийских подданных. Перед началом Первой мировой войны на территории губернии прожи-

${ }^{1}$ Статистический ежегодник России. 1914 г. Пг., 1915. Отд. I. С. 33-57. URL : http://www. mysteriouscountry.ru/wiki/ index.php.

\section{Baikal Research Journal}

электронный научный журнал Байкальского государственного университета 
вала прослойка немецких и австрийских граждан, имеющих, как правило, здесь свой бизнес. Они были объявлены военнопленными и заключены под стражу. Как следует из опубликованного дневника И. И. Серебренникова, первоначально в Иркутске они содержались в Крестовоздвиженском училище [2, с. 23].

Одновременно осуществлялась замена немецких названий населенных пунктов на русские [3, с. 81-82], а 15 ноября 1914 г. была запрещена пересылка и переводы денежных сумм, ценных бумаг, благородных и драгоценных камней «неприятельским подданным и учреждениям, находившимся вне пределов России». Преследование не касалось предпринимателей-славян, являвшихся подданными Германии и Австро-Венгрии, и православных подданных Турции. Со второго полугодия 1915 г. предприятия иностранцев-выходцев из неприятельских стран были ликвидированы, переданы в казну, а затем часть из них проданы частным лицам [4, с. 72-75]. Таким образом, в годы Первой мировой войны российские власти национализировали предприятия, принадлежавшие этническим немцам, подданным Германии и Австро-Венгрии. Кроме того, в соответствии с политикой трудового протекционизма запрещалось применение труда иностранных рабочих на государственных предприятиях и регламентировалось его использование в частной промышленности. Вместе с этим запрещался прием на работу лиц, не имеющих права проживания в данной местности. Так, 2 сентября 1916 г. иркутским генерал-губернатором А. Пильцем было подписано специальное распоряжение по этому поводу [5, с. 165-168].

В советский период слоя предпринимателей и просто граждан Германии на территории Иркутской области не имелось, но аналогичные меры наблюдались в отношении советских граждан немецкого происхождения. Они лишались гражданства СССР (им выдавался «вид на жительство»), как лишенные гражданства, исключались из рядов ВКП(б), подлежали увольнению из рядов Красной армии, органов власти [1, с. 183-184]. По указу Президиума Верховного Совета «О переселении немцев, проживающих в Поволжье» от 28 августа 1941 г. было депортировано с конфискацией имущества 950 тыс. немцев [6, с. 9].

Множество параллелей отслеживается в области социальной политики государства, особенно в поддержке наименее социально защищенных групп, а также в организации помощи фронту продуктами, вещами, деньгами, драгоценностями.

$\mathrm{C}$ началом Первой мировой войны к решению проблемы социальной помощи семьям военнослужащих активно подключились местные управы и общественные организации. Создается общественная комиссия по обследованию семейного и имущественного положения семейств нижних чинов, призванных на действительную службу, открывается сбор пожертвований деньгами и вещами [2, с. 29]. К середине ноября 1914 г. в сельских местностях Иркутской губернии действовали 66 комитетов и волостных попечительств по оказанию помощи семьям военнослужащих [Там же, с. 47]. Их средства слагались из членских взносов, пожертвований, ассигнований сельскими обществами и товариществами, сбора в церквях и учреждениях, устройства концертов, продажи флажков и т. д. [Там же, с. 48].

Иркутским комитетом Всероссийского союза городов регулярно проводись компании по сбору вещей и продуктов для раненных и больных воинов, пострадавшего населения, наших военнопленных. Эти акции тщательно планировались. Город делился на участки. В каждом участке сбор проводился один день, и заведовали им особо избранные от членов комитета и попечительства. В их распоряжении находились сборщики, фургоны, телеги. Пожертвованные вещи укладывались в специальные ящики. Одни ящики предназначались для продуктов, другие - для новых вещей, третьи - для старых вещей. Старые вещи отправлялись в дезинфекционные пункты. Привозимые вещи сдавались под расписку дежурящим в складах членам комитета по описи. Гражданам, которые жертвовали вещи, выдавалась специаль-

\section{Baikal Research Journal}

электронный научный журнал Байкальского государственного университета 
ная квитанция, в которой расписывались подробно все вещи. На квитанцию ставилась печать комитета и подпись сборщика. Сбор вещей происходил только на улицах и во дворах. Сборщикам не разрешалось входить в квартиры граждан. Каждый сборщик был в особом фартуке или белом халате со специальным значком с красным крестом в центре. Телеги украшались флагами и плакатами. Все участники акции перед началом кампании собирались в городской управе, где проводился молебен [2, с. 112-113].

Организация помощи семьям военнослужащих, фронтовикам, инвалидам в период Великой Отечественной войны имела свои особенности. Нет свидетельств, чтобы ее организация осуществлялась в столь торжественной обстановке. Кроме того, эта работа проводилась с опорой на трудовые коллективы и жестко фиксировалась по административной линии. Сбор вещей проводился по командам и разнарядкам, которые поступали на предприятия и организации с указанием чего и сколько сдать. Это же имело место и при проведении денежных займов у населения.

Очевидно, что в условиях жесткой централизованной системы управления по-другому не могло происходить. Одновременно это не означает, что усилия власти в данном направлении не опирались на широкий встречный отклик самого населения. Огромное количество архивных документов подтверждают вполне лояльное отношение жителей области к вопросам оказания помощи, но в данном случае огромное значение имел административный ресурс, чего не было в период Первой мировой войны.

Как и в годы Великой Отечественной войны, жители губернии принимали участие в помощи территориям, которые оказались непосредственно в зоне боевых действий. В годы Первой мировой неоднократно на территории области организовывался сбор средств населению Польши, как наиболее пострадавшему региону. Первый такой сбор был организован в Иркутске с 8 по 14 ноября 1915 г. От жителей губернии было отправлено 5 вагонов разного рода вещей [2, с. 69$]$. Прием пожертвований проводился в помощь разоренному населению Галиции, Сербии, Черногории, а также в пользу беженцев армян. Однако уже в 1916 г. происходит довольно резкое сокращение помощи. Газета «Иркутские губернские ведомости» писала, что «попытки организовать такого рода помощь путем сбора добровольных пожертвований не дали значительных средств и не привлекли достаточного внимания отдельных благотворителей». В газетном материале это объясняется тем, что изнурительная война продолжалась уже третий год, ее огромные расходы легли тяжелым бременем на плечи каждого [7, с. 1].

Отметим, что уже через год после начала войны цены на товары первой необходимости в Иркутске резко выросли. В частности, цена на чай, обувь, спички выросла в два раза, грубое сукно - на $125 \%$, табак — на 80 \% , сахар — на 40 \% [8, с. 288]. Из-за погодных условий 1916 г. оказался неурожайным, что еще более усугубило проблему продовольственного снабжения. В этих условиях социальная помощь не только регионам, пострадавшим от военных действий, но и прибывшим в Иркутскую губернию эвакуированным практически оказалась свернутой. Помощь по казенной линии сохранялась, но рост цен практически сводил эту помощь к нулю.

В годы Великой Отечественной войны население области также помогало в восстановлении оккупированных территорий, поддержка же населению освобождаемых советской армией других государств оказывалась в основном по государственной линии. Населению в это время уже практически нечего было жертвовать.

Анализ данных факторов условий жизни населения свидетельствует о существенных различиях на «входе» и «выходе» из этого 30-летнего периода. Отличалась технология оказания помощи населению. В условиях Первой мировой войны общественные организации обладали реальной самостоятельностью, могли не толь-

\section{Baikal Research Journal}

электронный научный журнал Байкальского государственного университета 
ко инициировать от своего имени работу в данном направлении, но и организовывать ее. В годы Первой мировой войны создавались и кооперативные организации, которые занимались заготовкой продуктов питания для нужд фронта. В годы же Великой Отечественной войны данная работа возлагалась на государственные предприятия и учреждения, колхозы в форме разнарядки, т. е. эта работа разворачивалась с опорой на административный ресурс.

Оказание всевозможной помощи отличается временными рамками. Если в годы Великой Отечественной войны помощь оказывалась на протяжении всей войны в самых различных формах, то в период Первой мировой войны различные сборы и пожертвования в губернии были фактически свернутыми к концу 1915 г. Масштабы поддержки со стороны населения были несопоставимо большими в годы Великой Отечественной войны. Практически все население области на протяжении войны участвовало в оказании всевозможной помощи, отдавая последнее, самое необходимое в повседневной жизни. Одновременно жители области принимали участие в укреплении финансовой мощи страны (подписка на заем, участие в денежно-вещевой лотереи, сбор средств в фонд вооружений для Красной Армии).

Особенно наглядно проведение социальной политики российского государства на «входе» и «выходе» применительно к такой группы населения, как инвалиды войны. Образование этой специфической социальной группы в регионе произошло в ходе Первой мировой войны, и ее наличие требовало от властей комплекса определенных мероприятий по социальной адаптации ее членов, а также оказание посильной помощи. Для небогатых сельских жителей инвалиды являлись обузой, поэтому многие из них были вынуждены возвращаться из деревень обратно в приют и просить помощи. Резко выросло число нищих-калек. Одновременно часть инвалидов обращалась с просьбой о приобщении их к определенному ремеслу сапожному, портному, кузнечному. От них поступали просьбы оказать помощь в приобретении грамоты. Только в сентябре 1916 г., т. е. спустя два года после начала войны, в губернии принимается решение о создании Инвалидного дома [2, с. 142]. При этом выяснилось, что учет инвалидов войны не ведется, а их общая численность неизвестна.

В годы Великой Отечественной войны такой учет не только был налажен, но и помощь со стороны органов власти и местного населения носила разносторонний, а главное, плановый характер. 6 ноября 1941 г. Совет народных комиссаров СССР принял постановление «О мероприятиях по трудовому устройству и обучению инвалидов Отечественной войны, а 6 мая 1942 г. «О трудовом устройстве инвалидов Отечественной войны». В соответствии с данными постановлениями в каждом регионе страны, в том числе и в Иркутской области, были созданы областные комиссии, занимавшиеся этими вопросами. Были налажены различные формы профессионального обучения инвалидов (госпитальная, индивидуальная, в спецдомах, в учебных заведениях). Трудоустройство инвалидов войны происходило практически во все отрасли народного хозяйства, причем лишь незначительная их часть были заняты в кооперации инвалидов.

Большая работа велась по оказанию материально-бытовой помощи инвалидам войны. Она включала сбор различных вещей и одежды, ремонт квартир, подвоз дров и угля, создание касс взаимопомощи, отдельных столов снабжения, специальных домов и интернатов, лечение, включая предоставление путевок на курорты и в санатории [1, с. 153-154]. На начало 1946 г. в области насчитывалось12 719 инвалидов Отечественной войны, из них было устроено на работу 9856 чел. и обучалось 404. Не было трудоустроено 587 чел. инвалидов третьей группы, которые по законам того времени были обязаны работать. Оказываемая всевозможная помощь инвалидам в период Отечественной войны была несравненно выше, чем в годы Пер-

\section{Baikal Research Journal}

электронный научный журнал Байкальского государственного университета 
вой мировой (тогда в условиях надвигавшегося гражданского хаоса данная группа населения оказалась, по сути, брошенной).

Тыловые районы решали еще одну чрезвычайно важную задачу - прием раненных с места боевых действий. С одной стороны, деятельность в данном направлении влияла на положение такой специфической группы населения, как раненные фронтовики, с другой стороны, это было дополнительной нагрузкой на и без того скудные ресурсы социальной помощи региона.

Как следует из документов, в первые недели войны местные власти в Иркутской губернии ориентировались на прием значительного количества раненных. Однако как показали дальнейшие события, планируемые мероприятия в отношении возможного приема раненных и все тревоги, связанные с этим, носили преждевременный характер. Раненных на фронтах Первой мировой войны в Иркутск не эвакуировали, и потребности в организации дополнительных местных лазаретов не возникло.

Основная деятельность в этом направлении была реализована в иной форме: уже к началу 1915 г. благодаря усилиям Иркутского комитета Российского общества Красного креста был устроен и отправлен на фронт первый иркутский лазарет на 100 мест [2, с. 68]. Кроме того, в Иркутске был создан Питательный пункт и Приют для прибывающих эвакуированных с фронта воинов. Здесь они могли несколько дней отдохнуть, сходить в баню, сменить белье, получить бесплатное довольствие. Приют был рассчитан на 20 коек и принял первых постояльцев 14 февраля 1915 г. [2, с. 89]. До 7 марта через приют прошло 71 чел. Большинство останавливались на 1-3 дня. Актуальность этой проблемы объяснялась тем, что от Челябинска до Иркутска не было ни одного остановочного пункта. Все это расстояние воины проезжали, не выходя из вагонов, а многим нужно было ехать дальше в Амурскую или Приморскую области.

Одновременно в мае 1915 г. городская управа принимает решение об устройстве в городе госпиталя для больных и раненных воинов Иркутской губернии [2, с. 93]. Первые раненые появились в Иркутске в январе 1915 г. Тогда же в городе был создан попечительский комитет по размещению раненых и оказанию им помощи и организован сбор средств на их содержание. Иркутское отделение Красного креста выделило из своего фонда 5000 р. на открытие лазарета на 14 коек при Мариинской общине, а Иркутское отделение Сибирского общества помощи больным и раненым в феврале 1915 г. совместно с комитетом Союза российских городов открыли несколько больничных приютов, в которых с 15 февраля по 1 сентября лечилось 562 раненых иркутян [8, с. 138].

Организация лечебного дела в Иркутске в годы Великой Отечественной войны была несопоставимо масштабнее, чем в годы Первой мировой. Как явствует из докладной записки начальника отдела эвакогоспиталей областного отдела здравоохранения, датированной 7 марта 1945 г., в области на это время размещалось 20 эвакогоспиталей, из них 15 непосредственно в г. Иркутске. Вне Иркутска госпитали размещались в Слюдянке (на 200 коек), Зима (на 200 коек), Свирске (на 250 коек), Тулуне (на 200 коек), курорт Усолье (на 600 коек). Вся штатная коечная сеть области составляла на этот период 7000 коек и еще 1400 временных [9, с. 175-176]. Таким образом, социальная нагрузка на регион в данный период была несопоставимо выше, так как включала организацию прачечного дела, заготовку дров, поиск дополнительных продуктов питания и многое другое.

В годы Первой мировой войны Иркутская губерния была вынуждена принять огромное число военнопленных, что также стало серьезным фактором, влиявшим на социальное положение местного населения. Основная масса военнопленных была размещена вне столицы губернии: на станции Иннокентьевская (ныне это Ир-

\section{Baikal Research Journal}

электронный научный журнал Байкальского государственного университета 
кутск II) -5400 чел., в г. Нижнеудинске -1000. Как Иркутск, так и губерния оказались в более выигрышном положении в сравнении с соседними регионами. Например, в г. Красноярске на этот же период насчитывалось 12000 военнопленных, в Ачинске - 2300 чел., в Канске -5500 чел. [2, с. 15], т. е. соседний регион принял военнопленных в три раза больше, чем Иркутская губерния. Использование контингента военнопленных на различных работах в губернии в тех условиях было ограниченно, особенно в зимний период. В то же время содержание контингента военнопленных являлось серьезной социальной нагрузкой на регион. Наиболее широкое применение на городских промышленных предприятиях труда военнопленных достигло в 1916-1917 гг. Военнопленные на частные предприятия направлялись по заявке владельцев, их охрана обеспечивалась местной полицией, а численность не должна была превышать 15 \% от числа работающих [10, с. 198].

В годы Великой Отечественной войны партии военнопленных в Иркутскую область были направлены уже после окончания войны. Как следует из решения Иркутского облисполкома «О распределении военнопленных немцев для работы на предприятиях области» от 4 июня 1945 г., всего область должна была принять 15 тыс. немецких военнопленных, которые размещались в 14 лагерях [9, с. 184-186]. В послевоенный период в область прибыл и большой контингент японских военнопленных, а также репатриированного населения из западных районов страны.

Важной составляющей условий жизни населения являлась помощь эвакуированному населению.

Первые беженцы в губернию стали прибывать осенью 1915. К концу 1915 г. поток беженцев неуклонно возрастал и составил 9052 чел. [11, с. 113]. Трудоспособными являлась лишь половина прибывшего контингента беженцев, из них $75 \%$ не имели работы и существовали за счет пайков и благотворительной помощи; 80 \% беженцев являлись крестьянами и не могли себе найти работу в городах. В связи с этим, в марте 1916 г. Министерство внутренних дел принимает решение, согласно которому всех беженцев из крестьян рекомендовалось расселять в сельские местности, где «они могли бы заняться привычным для них сельскохозяйственным трудом». Уклоняющихся от сельхозработ предписывалось наказывать лишением пайка и квартир.

На питание беженцев выделялось 30 к. в сутки, переезд на подводах до населенного пункта осуществлялся из расчета 2 к. за версту, на баню и мыло - по 10 к. в месяц на человека [2, с. 135-136]. Однако масштабы деятельности по оказанию помощи беженцам сокращались, и уже в 1917 г. помощь оказывалась адресная только тем, кто находился в наиболее бедственном положении. Это касалось вдов с малолетними детьми, инвалидов, калек и т. д. К этому времени положение широких слоев населения уже практически ничем не отличалось от условий, в которых проживали беженцы.

В годы Великой Отечественной войны перемещение эвакуированного населения и его размещение регламентировалось органами власти. Основной контингент эвакуированных прибыл со своими предприятиями и практически сходу включился в работу, а основная масса эвакуированных - в течение первого года войны. На начало 1943 г. на территории Иркутской области проживало 24 тыс. эвакуированных [1, с. 175], что в три раза превышало аналогичный показатель в годы Первой мировой.

Кроме эвакуированных на территорию области из других регионов прибывали тысячи людей в рамках так называемого планового перемещения, которых селили в основном в сельской местности, и в местах рыбозаводов.

Еще одним отрядом переселенцев на территории области в годы Отечественной войны были так называемые рабочие и строительные колонны, состоящие в основ-

\section{Baikal Research Journal}


ном из таджиков, узбеков, казахов. На начало 1944 г. их численность по Иркутской области превышала 3 тыс. чел. [1, с. 180]. Следовательно, социальная нагрузка на местное население, за счет которого прежде всего требовалось изыскать продукты питания и товары первой необходимости, в годы Великой Отечественной войны являлась значительно выше.

Можно констатировать, что на социальное положение населения региона в период мировых войн оказывали воздействие идентичные факторы. Совпадение этих факторов обусловлено тем, что регион в обоих войнах являлся глубоким тылом, а также тем, что промежуток между войнами был совсем небольшой - чуть больше 20 лет. Однако степень влияния отдельных факторов существенно отличается. Практически все отмеченные явления в период Великой Отечественной войны носили гораздо более масштабный характер и, следовательно, оказывали более серьезное воздействие на социальное положение населения.

Тем не менее, влияние этих факторов не сказалось на социальной стабильности и не имело тех политических последствий, которые в конечном итоге завершились массовым дезертирством с фронта и катастрофой для Российской империи. Советская мобилизационная система оказалась более эффективной в области решения социальных проблем и сглаживания негативного влияния войны на условия жизни. $K$ тому же распределительная система в совокупности с теми общественными отношениями, которые оформились в основном в $1930-е$ гг., нивелировали социальные различия, не позволяли откровенно наживаться отдельным слоям населения, как это было с буржуазией в годы Первой мировой войны. Если в начальный период войны в решении социальных проблем активное участие приняли структуры гражданского общества губернии, то по мере ухудшения материально-бытового положения населения их деятельность была свернута - именно тогда, когда помощь со стороны имущих слоев была в наибольшей степени востребована, она перестала оказываться. С другой стороны, политическая хаотизация и нерешительность государства, так и не сумевшего пойти на жесткие ограничения в политической сфере на период войны, в конечном итоге свели на нет усилия органов власти в области социального обеспечения семей военнослужащих, инвалидов, беженцев.

Сказывался и невысокий уровень развития промышленного потенциала губернии, на базе которого можно было улучшить материальное положение населения непосредственно в регионе. В годы Великой Отечественной войны органы власти имели гораздо больше возможностей на основе имеющегося в регионе экономического потенциала развивать местную промышленность, используя местное сырье и отходы основного производства предприятий союзного и республиканского подчинения. Это позволило сглаживать негативные последствия войны на социально-бытовую инфраструктуру, обеспечить население простейшими товарами первой необходимости (более подробно см.: [12]). Нет никаких свидетельств, что местные органы власти Иркутской губернии пытались подобным образом решать проблемы снабжения населения в годы Первой мировой войны.

Таким образом, если социальное положение населения в условиях обоих войн определялось во многом совпадающими факторами, то характер социальной политики в условиях Великой Отечественной войны имел принципиальные отличия. Эти различия были обусловлены характером политического режима и тем типом личности, который был сформирован в межвоенный период, особенно в 1930 -е гг. Именно в силу их Советский Союз не только устоял, несмотря на то, что разрушения и социальные нагрузки на население были несопоставимо большими, но и победил объединенную Европу, реализовал ракетно-ядерный проект и утвердился в статусе сверхдержавы.

\section{Baikal Research Journal}

электронный научный журнал Байкальского государственного университета 


\section{Список использованной литературы}

1. Шалак А. В. Социальные проблемы населения Восточной Сибири (1940-1950 гг.) : монография / А. В. Шалак. - Иркутск : Изд-во Иркут. гос. экон. акад., 2000. - 356 с.

2. Первая мировая война в документах Государственного архива Иркутской области : сб. док. / сост.: О. Т Базалийская, Е. В. Ильина, М. В. Михайлова. - Иркутск : Оттиск, 2014. $272 \mathrm{c}$.

3. Малиновский Л. В. История немцев в России / Л. В. Малиновский. - Барнаул : Алтай, 2008. $-175 \mathrm{c}$.

4. Шайдуров В. Н. Ликвидационное законодательство Российской империи и его влияние на формирование немецкой диаспоры в Сибири в начале XX в. / В. Н. Шайдуров // Немцы в Сибири: история, язык, культура : материалы Междунар. науч. конф. Красноярск, 13-16 окт. 2004 г. / отв. ред. В. А. Дятлова. - Красноярск : Краснояр. гос. пед. ун-т им. В. П. Астафьева, 2004. - С. 72-75.

5. Коробченко А. И. Политика Российских властей в отношении предпринимателей враждебных держав на Востоке страны в годы Первой мировой войны / А. И. Коробченко // Иркутский историко-экономический ежегодник: 2010. — Иркутск : Изд-во БГУЭП, 2010. С. $165-168$.

6. Земсков В. Н. Репатриация советских граждан и их дальнейшая судьба (19461956 гг.) / В. Н. Земсков // Социологические исследования. - 1995. — № 5. - С. 3-13.

7. Мигалев П. Иркутск в годы Первой мировой войны / П. Мигалев // Байкальские вести. - 2014. - 28 июля.

8. Иркутская летопись. 1661-1940 гг. / сост. Ю. П. Колмаков. - Иркутск : Оттиск, 2003. $-848 \mathrm{c}$.

9. Великая Отечественная война по материалам Государственного архива Иркутской области : сб. док. / сост. О. Т. Базалийская [и др.]. - Иркутск : Оттиск, 2015. - 320 с.

10. Неклюдова А. В. Рынок труда в городах Восточной Сибири в годы Первой мировой войны / А. В. Неклюдова // Иркутский историко-экономический ежегодник: 2010. - Иркутск : Изд-во БГУЭП, 2010. - С. 165-168.

11. Мантурова С. Ч. Социальное призрение беженцев в Забайкалье в годы Первой мировой войны / С. Ч. Мантурова // Иркутский историко-экономический ежегодник: 2005. Иркутск : Изд-во БГУЭП, 2005. - С. 112-115.

12. Фомина Ю. А. Промышленность местного подчинения Байкальского региона накануне и в годы Великой Отечественной войны (1939-1945 гг.) / Ю. А. Фомина, А. В. Шалак. Иркутск : Изд-во БГУЭП, 2009. - 286 с.

\section{References}

1. Shalak A. V. Sotsial'nye problemy naseleniya Vostochnoi Sibiri (1940-1950 gg.) [Social problems of the Eastern Siberian population (1940-1950)]. Irkutsk State Economics Academy Publ., 2000. 356 p.

2. Bazaliiskaya O. T., Ilyina E. V., Mikhailova M. V. (eds). Pervaya mirovaya voina $v$ dokumentakh Gosudarstvennogo arkhiva Irkutskoi oblasti [The First World War in documents of the Irkutsk Oblast State Archive]. Irkutsk, Ottisk Publ., 2014. 272 p.

3. Malinovsky L. V. Istoriya nemtsev $v$ Rossii [History of Germans in Russia]. Barnaul, Altai Publ., 2008. 175 p.

4. Shaidurov V. N. Liquidation legislation on the Russian empire and its impact on developing the German diaspora in Siberia in early XX century. In Dyatlova V. A. (ed.). Nemtsy $v$ Sibiri: istoriya, yazyk, kul'tura. Materialy Mezhdunarodnoi nauchnoi konferentsii. Krasnoyarsk, 13-16 oktyabrya 2004 g. [Germans in Siberia: history, language, culture. Materials of International Research Conference. Krasnoyarsk, October 13-16, 2004]. Krasnoyarsk State Pedagogical University named after V. P. Astafyev Publ., 2004, pp. 72-75. (In Russian).

5. Korobchenko A. I. Policy of Russian authorities in regard of entrepreneurs of hostile super powers in the east of the country during the First War War. Irkutskii istoriko-ekonomicheskii ezhegodnik. 2010 [Irkutsk Historical and Economic Yearbook. 2010]. Irkutsk, Baikal State University of Economic and Law Publ., 2010, pp. 165-168. (In Russian).

6. Zemskov V. N. Repatriation of Soviet citizens and their further fate of (1946-1956). Sotsi ologicheskie issledovaniya = Sociological Studies, 1995, no. 5, pp. 3-13. (In Russian).

\section{Baikal Research Journal}


7. Migalev P. Irkutsk during the First Word War. Baikal'skie vesti, 2014, July 28. (In Russian).

8. Kolmakov Yu. P. (ed.). Irkutskaya letopis'. 1661-1940 gg. [Irkutsk Annals. 1661-1940]. Irkutsk, Ottisk Publ., 2003. 848 p.

9. Bazaliyskaya O. T. et al. (eds). Velikaya Otechestvennaya voina po materialam Gosudarstvennogo arkhiva Irkutskoi oblasti [The Great Patriotic War adapted from the State Archive of Irkutsk Oblast ]. Irkutsk, Ottisk Publ., 2015. 320 p.

10. Neklyudova A. V. Labor market in towns of Eastern Siberia during the First World War. Irkutskii istoriko-ekonomicheskii ezhegodnik. 2010 [Irkutsk Historical and Economic Yearbook. 2010]. Irkutsk, Baikal State University of Economic and Law Publ., 2010, pp. 165-168. (In Russian).

11. Manturova S. Ch. Social care of refugees in Zabaikalye. Irkutskii istoriko-ekonomicheskii ezhegodnik. 2005 [Irkutsk Historical and Economic Yearbook. 2005]. Irkutsk, Baikal State University of Economic and Law Publ., 2005, pp. 112-115. (In Russian).

12. Fomina Yu. A., Shalak A. V. Promyshlennost' mestnogo podchineniya Baikal'skogo regiona nakanune i $v$ gody Velikoi Otechestvennoi voiny (1939-1945 gg.) [Local industry of Baikal Region before and during the Great Patriotic War (1939-1945)]. Irkutsk, Baikal State University of Economic and Law Publ., 2009. 286 p.

\section{Информация об авторе}

Шалак Александр Васильевич - доктор исторических наук, профессор, заведующий кафедрой истории и международных отношений, Байкальский государственный университет, 664003, г. Иркутск, ул. Ленина, 11, e-mail: Shalak-av@isea.ru.

\section{Author}

Aleksandr V. Shalak - Doctor habil. (History), Professor, Head of Chair of History and International Relations, Baikal State University, 11 Lenin St., 664003, Irkutsk, Russian Federation; e-mail: Shalak-av@isea.ru.

\section{Библиографическое описание статьи}

Шалак А. В. Население Иркутской области: особенности социального положения в период мировых войн / А. В. Шалак // Baikal Research Journal. - 2016. — T. 7, № 4. — DOI : 10.17150/2411-6262.2016.7(4).21.

\section{Reference to article}

Shalak A. V. Population of Irkutsk Oblast: features of social standing during the period of world wars. Baikal Research Journal, 2016, vol. 7, no. 4. DOI : 10.17150/2411-6262.2016.7(4).21. (In Russian).

\section{Baikal Research Journal}

